\title{
TWO MERMITHERGATES OF ECTATOMMA
}

\section{By William MoRToN WheELER ${ }^{1}$}

Since the publication in 1928 of my review of the modifications induced by Mermis parasites in various species of ants, two additional cases have been reported, one by Strelnikov (1928) in a Ponerine ant, Pachycondyla striata, from Paraguay, and one by myself (1929) in a Formicine ant, Camponotus (Tanæmyrmex) punctatus from Argentina. Two other interesting mermithergates have just come to light among some ants collected by Mr. Nathan Banks and Mr. P. J. Darlington. One of these belongs to the typical Ectatomma tuberculatum Olivier, the other to its variety punctigerum Emery. As long ago as 1890, Emery $(1890 a)$ mentioned a peculiar worker of the typical $E$. tuberculatum, which we now know must have been a mermithergate, but he merely cites it as "analogous" to a similar specimen of Neoponera villosa with small head and voluminous abdomen.

The mermithized specimen of the typical E. tuberculatum was taken by Mr. Banks on July 15, 1924, near the tropical laboratory on Barro Colorado Island, Panama. It measures nearly $16 \mathrm{~mm}$. and is of the same brownish ferruginous color as normal workers from the same locality, but with the gaster distinctly darker. The head is smaller and narrower, with scarcely an indication of the posterior angles and with very slightly larger and more convex eyes. Ocelli lacking. Antennal scapes extending half their length beyond the posterior corners of the head and the mandibles slightly narrower. Thorax shaped as in the normal worker but slightly less robust, with distinct, blunt teeth on the epinotum. Petiolar node more strongly compressed anteroposteriorly. Postpetiolar and gastric segments, especially

${ }^{1}$ Contribution from the Entomological Laboratory of the Bussey Institution, Harvard University, No. 334. 
the first, enlarged and distended with Mermis. Legs decidedly longer than in the normal worker.

Head sculpture peculiar in that the longitudinal rugæ are finer, closer together and decidedly more numerous on the front than in the normal worker. The reticulate rugæ on the sides of the vertex in the latter are also replaced by such longitudinal rugæ. Thoracic sculpture as in the normal worker. Petiolar node transversely rugulose and not irregularly rugose above. Postpetiole and gaster more opaque throughout, finely and densely striate, with a satiny lustre; the striæ transverse and converging behind on the postpetiole, longitudinal on the gastric segments. Venter more shining but very finely and transversely, though more superficially striate throughout. The sculpture of the abdomen therefore resembles that of the normal worker tuberculatum. The pilosity of the mermithergate is quite normal.

Although the typical form of E. tuberculatum is a common ant over a large portion of the Neotropical Region from Southern Mexico to Southern Brazil, its two varieties, acrista Forel and punctigerum Emery have a much more restricted distribution. The var. acrista is known only from Paraguay; Emery $(1890$ b) described punctigerum from a couple of workers taken by Simon at San Esteban, Venezuela. It is certainly the common, if not the only form of the species in Trinidad, where it has been taken by Prof. R. Thaxter and myself, and Dr. George Salt and Mr. Darlington brought me specimens of it from Northern Colombia. The worker differs from that of the typical tuberculatum in coloration, being decidedly darker and more brownish, and in the sculpture of the postpetiole and first gastric segment, the coarse, sparse punctures on which are larger, more impressed and interrupt the striated sculpture. Moreover, the striation on the first gastric segment is much feebler than in the typical tuberculatum and becomes obsolete on the sides, so that the whole segment is decidedly smoother and more shining. The female punctigerum (undescribed) is scarcely paler than the worker, with very similar abdominal sculpture though in some specimens the striation on the first gastric segment is even 

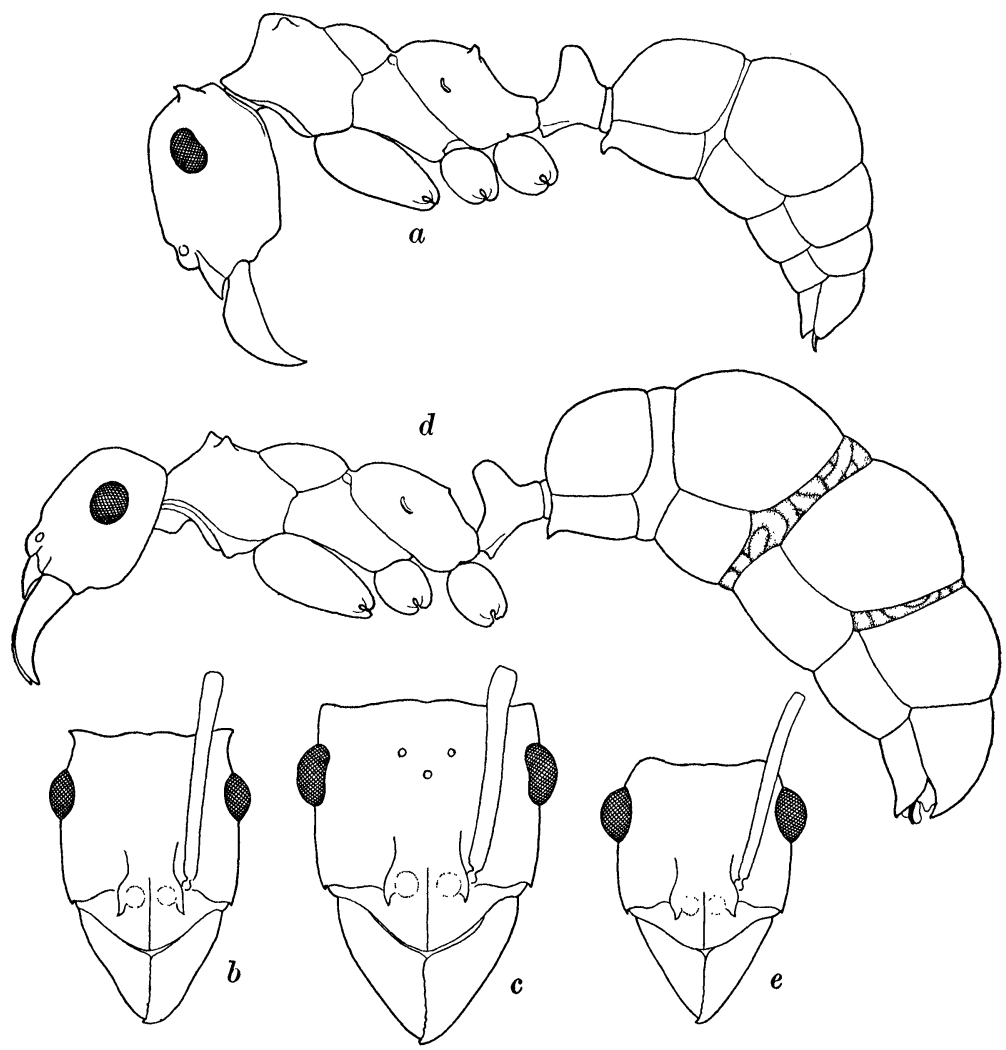

Fig. 1. Ectatomma tuberculatum Olivier var. punctigerum Emery. $a$, normal worker in profile; $b$, head of same, dorsal view; $c$, head of normal female; $d$, mermithergate in profile; $e$, head of same. 
feebler and the surface, therefore, even smoother and more shining.

The punctigerum mermithergate (Fig. 1d,e) was captured by Mr. Darlington on April 20, 1920 at St. Augustine, Trinidad, together with three normal workers of the variety. Were it not for this association the specific identity of the parasitized specimen might be doubtful, though its cephalic and thoracic sculpture is clearly of the $E$. tuberculatum type. The specimen measures $16.6 \mathrm{~mm}$. in length and is longer than the average normal worker which measures only about 10-12.5 mm., but the proportions of the head, thorax and abdomen are very different. In the mermithergate the head measures only $3.2 \mathrm{~mm}$. in length, including the mandibles, the thorax $4 \mathrm{~mm}$., the abdomen 9.4 $\mathrm{mm}$. The corresponding measurements of the normal large worker are: head $3.5 \mathrm{~mm}$., thorax $4.5 \mathrm{~mm}$., abdomen 4.5 $\mathrm{mm}$. Though the head and thorax resemble those of the normal worker they are therefore decidedly smaller and more slender. The head, excluding the mandibles, is nearly square, very slightly longer than broad, with very feebly rounded sides and the posterior angles merely rounded-rectangular and not sharply rectangular or even distinctly cornuate as in the normal worker. Eyes larger, more protuberant, nearly hemispherical. There are no traces of ocelli. Antennal scapes extending nearly half their length beyond the posterior corners of the head (only two-fifths in the normal worker), mandibles somewhat narrower. Besides its smaller and more slender dimensions the thorax differs from that of the normal worker in having the lateral tubercles of the pronotum more acute and less auriculate, the median tubercle or projection narrower and more sharply defined. The base and declivity of the epinotum form a less distinct obtuse angle and the epinotal teeth are reduced to mere denticles. Petiole very similar to that of the normal worker but the node slightly more compressed anteroposteriorly. Postpetiole and gaster much larger and more voluminous, owing to their containing a large Mermis, the compact coils of which are visible through the distended intersegmental membranes. The hypertrophy affects not only the postpetiole and first gastric segment but also the deflected second, third and fourth gastric segments, 
which in the normal worker and even in the female are much shorter and telescoped into one another. Anteroventral projection of the postpetiole less developed than in the normal worker and female; legs as long as those of the former.

Sculpture peculiar; the longitudinal rugæ on the front and vertex decidedly less coarse, denser and more numerous than in the normal worker, with the reticulate rugæ between the front and eyes also much finer; rugules on the median portion of the clypeus more numerous; striæ on the mandibles somewhat coarser. On the thorax the rugæ are distinctly finer and more definitely transverse; those on the posterior portion of the pronotum also transverse, not coarse and irregular as in the normal worker. The rugæ on the petiolar node are finer and symmetrical. On the postpetiole and gaster the sculpture is quite unlike that of $E$. tuberculatum and much like that of $E$. quadridens Fabr., the tergites of all the segments being finely and regularly striate, so that the surface is subopaque, with a faint satiny lustre. The striæ on the postpetiole are arcuate anteriorly, longitudinal in the middle and transverse posteriorly; on the first gastric segment longitudinal anteriorly and transverse behind; on the second and third gastric segments transverse and more oblique on the sides. The fourth segment is more shining, with finer and less distinct striæ. The coarse punctures on the postpetiole and first gastric segment are small, inconspicuous and scattered, as in $E$. quadridens and therefore very different from those of punctigerum or the typical tuberculatum.

Pilosity as in the normal punctigerum worker, but less abundant, especially on the abdomen.

Coloration decidedly darker; dark brown, almost blackish, with brownish yellow clypeus and mandibles, the former streaked with fuscous in the middle, the latter fuscous externally. Femora, terminal tarsal joints, tips of scapes, apical halves of antennal funiculi and borders of gastric segments reddish brown; a spot on the middorsal region of the postpetiole and one on the corresponding region of the first gastric-segment more yellowish.

The specimens described in the preceding paragraphs are obviously modified workers, without any perceptible female 
(queen) characters. Even the enlargement of the abdomen is quite unlike that of the normal Ectatomma female, since in this caste the gaster is shaped like that of the worker, though more voluminous, especially in the region of the postpetiole and first gastric segment. The mermithergates are interesting for two reasons, first, because they so clearly illustrate the compensatory decrease in the size of the head and, in Darlington's specimen, also of the thorax as a result of the hypertrophy of the abdomen, which harbors the Mermis, and second, on account of their close resemblance in coloration, abdominal sculpture, and, I may add, also in the shape of the posterior portion of the head, to another species of the same genus, E. quadridens. This singular resemblance may, I believe, be most readily explained on the supposition that the specific characters of quadridens are probably more nearly those of the ancestral species of Ectatomma and that in the mermithized specimens these characters have been activated as a result of metabolic disturbances set up during metamorphosis by the parasite. To have produced such a pronounced effect on the characters of the adult ant, the young nematode must have entered its body cavity during the larval stage. Recently Vandel (1927) has maintained that in Pheidole pallidula infection of the prepupa by the Mermis is sufficient to produce a mermithergate, but his evidence for this contention is very meager. I have called attention to the fact (1928) that the larvæ of the Ponerinæ and Formiciæ (Lasius) spin cocoons before the prepupal stage and that it is therefore very improbable that the young nematode would wait to bore through a tough envelope when it could so easily and directly enter the unprotected, thin-skinned larva. That this is actually what happens, has been shown by Dr. N. A. Cobb, our well-known authority on the nematodes, who writes me that he has found the larva of Allomermis myrmecophila Bayliss- "in the body cavity of a queen grub of the dark-colored Lasius from Falmouth, Lasius niger neoniger." Falmouth, Massachusetts, is the locality in which Dr. A. H. Sturtevant found the many mermithized queens (mermithogynes) of Lasius described in my paper of 1928 . 


\section{Literature}

Emery, C. 1890. a. Studii sulle Formiche della Fauna Neotropica I. Formiche di Costa Rica. Bull. Soc. Ent. Ital. 22, 1890 , pp. $38-80$, 5pls.

Emery, C. 1890. b. Formicides. Voyage de M. E. Simon au Vénézuéla (Dec. 1887-April 1888) 7e Mém. Ann. Soc. Ent. France 1890, pp. 55-76.

Strelnikov, T. D. 1928. Mermis Parasitism in Pachydondyla triata. Psyche 35, 1928, pp. 199-200, 1 fig.

Vandel, A. 1927. Modifications determinées par un nematode du genre, "Mermis," chez les ouvrières et les soldats de la Fourmi "Pheidole pallidula" Nyl. Bull. Biol. France Belg. 61, 1927, pp. 38-48, 3 figs.

Wheeler, W. M. 1928. Mermis Parasitism and Intercastes among Ants. Journ. Experim. Zool. 50, 1928, pp. 165237, 17 figs.

Wheeler, W. M. 1929. A Camponotus Mermithergate from Argentina. Psyche 36, 1929, pp. 102-106, 1 fig. 

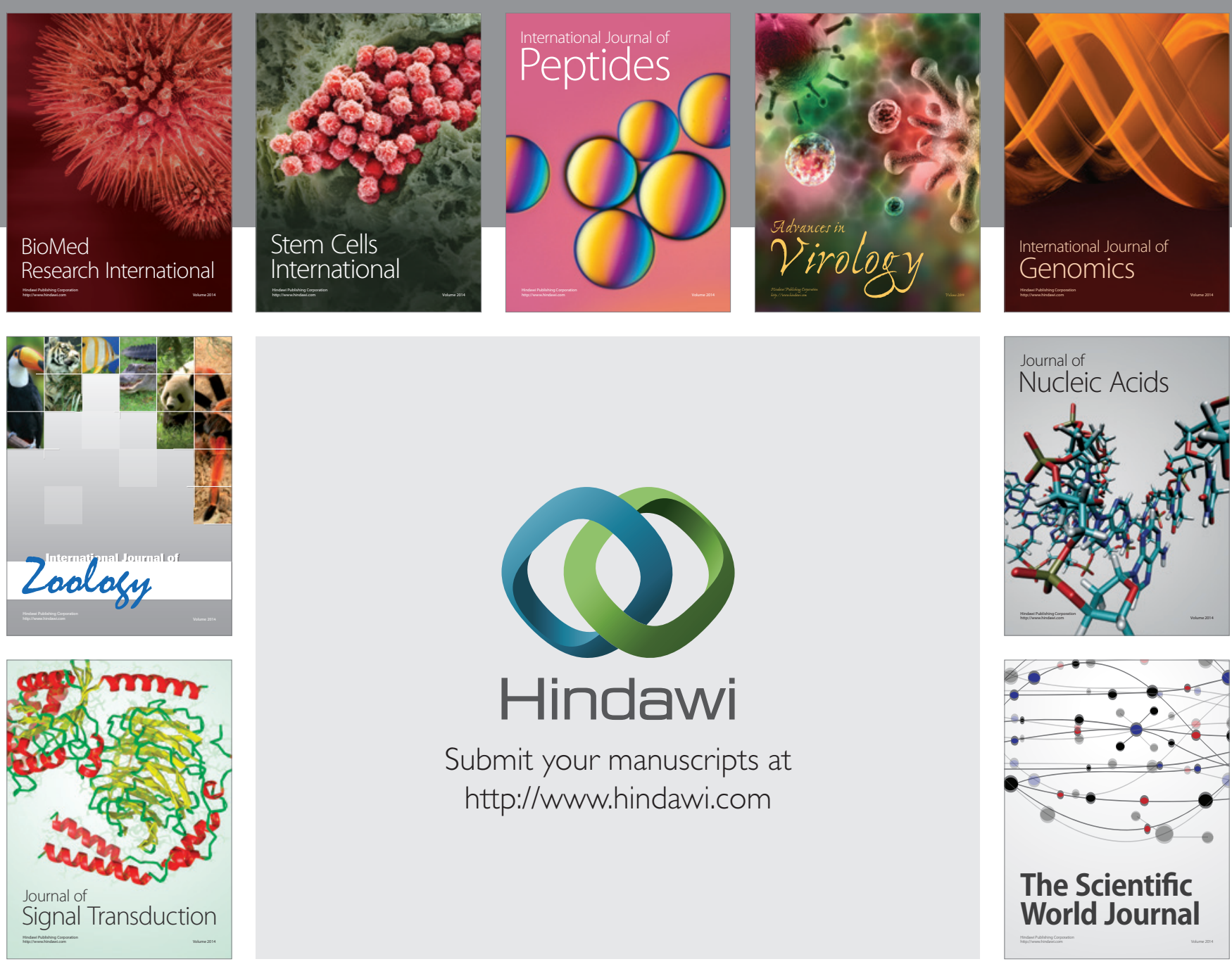

Submit your manuscripts at

http://www.hindawi.com
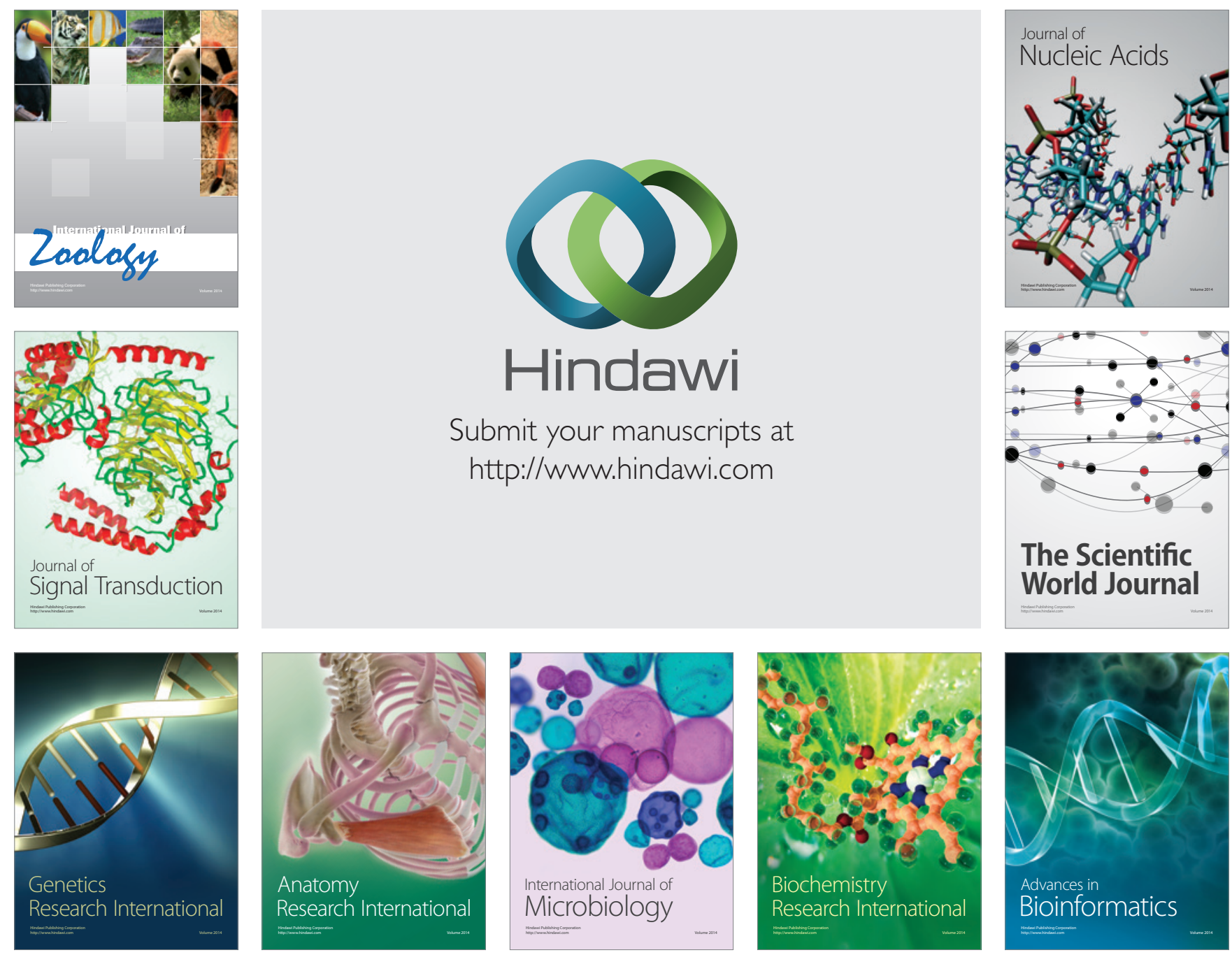

The Scientific World Journal
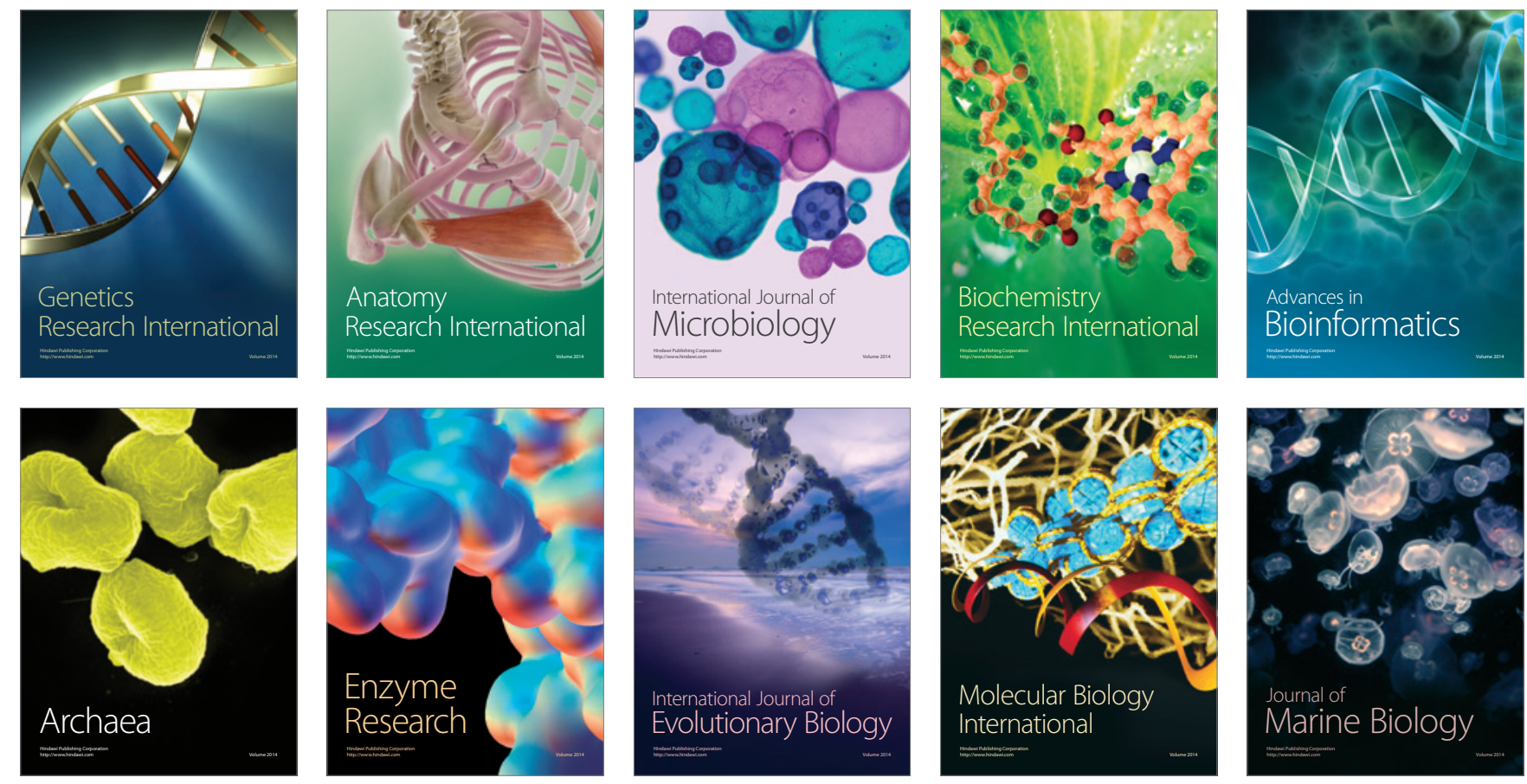